\title{
Life-cycle assessment of hydrogen production via catalytic gasification of wheat straw in the presence of straw derived biochar catalyst
}

\author{
Adrian Chun Minh Loy ${ }^{\mathrm{a}, 1, *}$, Hatem Alhazmi ${ }^{\mathrm{b}, 1}$, Serene Sow Mun Lock ${ }^{\mathrm{c}}$, Chung Loong Yiin ${ }^{\mathrm{d}}$, \\ Kin Wai Cheah ${ }^{\mathrm{e}}$, Bridgid Lai Fui Chin ${ }^{\mathrm{f}}$, Bing Shen $\mathrm{How}^{\mathrm{g}}$, Suzana Yusup ${ }^{\mathrm{a}}$ \\ ${ }^{a}$ HICoE - Centre for Biofuel and Biochemical Research, Institute of Self-Sustainable Building, Universiti Teknologi PETRONAS, Seri Iskandar, Perak 32610, Malaysia \\ ${ }^{\mathrm{b}}$ National Center for Environmental Technology (NCET), King Abdulaziz City for Science and Technology (KACST), P.O. Box 6086, 11442 Riyadh, Saudi Arabia \\ ${ }^{\mathrm{c}}$ CO2 Research Center (CO2RES), Department of Chemical Engineering, Universiti Teknologi PETRONAS, 32610 Seri Iskandar, Malaysia \\ ${ }^{\mathrm{d}}$ Department of Chemical Engineering and Energy Sustainability, Faculty of Engineering, Universiti Malaysia Sarawak (UNIMAS), Kota Samarahan, 94300, Sarawak, \\ Malaysia \\ ${ }^{\mathrm{e}}$ Energy and Environment Institute, University of Hull, Cottingham Road, Hull HU6 7RX, United Kingdom \\ ${ }^{\mathrm{f}}$ Department of Chemical Engineering, Faculty of Engineering and Science, Curtin University Malaysia, CDT 250, 98009 Miri, Sarawak, Malaysia \\ ${ }^{g}$ Research Centre for Sustainable Technologies, Faculty of Engineering, Computing and Science, Swinburne University of Technology, Jalan Simpang Tiga, 93350 \\ Kuching, Sarawak, Malaysia
}

\section{H I G H L I G H T S}

- The environmental impacts based on P5 unit are found to be negligible.

- P4 unit poses the highest environmental impact, especially on human health category.

- The whole process environmental impact is found to be $93.4017 \mathrm{mPt}$.

- "Wheat straw loading" parameter contributes the most to global warming potential.

- Straw biochar catalysts offer competitive $\mathrm{H}_{2}$ yield and lower environmental impact.

\section{A R T I C L E I N F O}

\section{Keywords:}

Life-cycle analysis

Biochar

Gasification

Hydrogen

Biomass
G R A P H I C A L A B S T R A C T

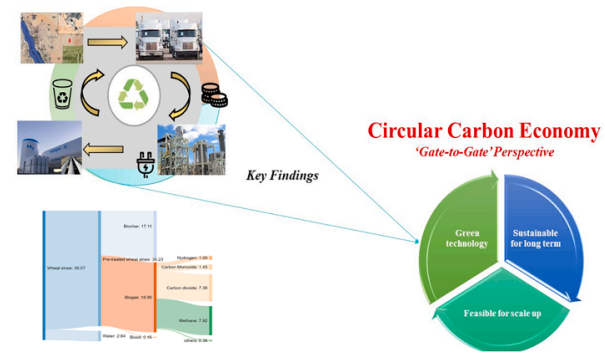

\footnotetext{
* Corresponding author.

E-mail address: adriaminh@gmail.com (A.C.M. Loy).

1 First and second author contributed equally in this work.
} 